\title{
Removal of organophosphate esters from municipal secondary effluent by ozone and $\mathrm{UV} / \mathrm{H}_{2} \mathrm{O}_{2}$ treatments
}

\author{
Xiangjuan Yuan a , Silvia Lacorte ${ }^{\mathrm{b}}$, Joyce Cristale ${ }^{\mathrm{b}}$, Renato F. Dantas ${ }^{\mathrm{c}}$, Carme Sans ${ }^{\mathrm{c}, *}$, Santiago Esplugas ${ }^{\mathrm{c}}$, \\ Zhimin Qiang ${ }^{\mathrm{a}, *}$
}

${ }^{a}$ Key Laboratory of Drinking Water Science and Technology, Research Center for Eco-Environmental Sciences, Chinese Academy of Sciences, 18 Shuang-qing Road, Beijing 100085, China

${ }^{\mathrm{b}}$ Department of Environmental Chemistry, IDAEA-CSIC, Jordi Girona 18-26, 08034 Barcelona, Spain

${ }^{\mathrm{c}}$ Department of Chemical Engineering, University of Barcelona, Martí $i$ Franquès 1, 108028 Barcelona, Spain

\section{A R T I C L E I N F O}

\section{Article history:}

Received 3 May 2015

Received in revised form 27 August 2015

Accepted 24 September 2015

Available online 28 September 2015

\section{Keywords:}

Organophosphate esters (OPEs)

Municipal secondary effluent

Advanced treatment

Ozone

$\mathrm{UV} / \mathrm{H}_{2} \mathrm{O}_{2}$

\begin{abstract}
A B S T R A C T
Organophosphate esters (OPEs) have emerged as a new class of contaminants due to their massive use as flame retardants and plasticizers. These contaminants are toxic to aquatic organisms and some of them are not biodegradable in wastewater treatment plants. This study investigated the degradation kinetics of eight typical OPEs during ozone and $\mathrm{UV} / \mathrm{H}_{2} \mathrm{O}_{2}$ treatments in Milli-Q water, humic acid (HA) solution, and municipal secondary effluent. The studied OPEs included three chlorinated: tris(2-chloroethyl) phosphate (TCEP), tris(chloropropyl) phosphate (TCPP) and tris(dichloropropyl) phosphate (TDCP); two aromatic: triphenyl phosphate (TPhP) and tricresyl phosphate (TCrP); and three aliphatic: tri-n-butyl phosphate (TnBP), tris(2-butoxyethyl) phosphate (TBEP), and tris(2-ethylhexyl) phosphate (TEHP). Results indicate that the degradation of target OPEs conformed to the pseudo-first-order kinetics and $\mathrm{UV} / \mathrm{H}_{2} \mathrm{O}_{2}$ was more effective than ozone for their elimination by comparing the overall removal efficiencies and energy consumptions. Two aromatic and two aliphatic OPEs (i.e., TPhP, TCrP, TnBP and TBEP) were effectively degraded by ozone and $\mathrm{UV} / \mathrm{H}_{2} \mathrm{O}_{2}$ in the test water matrices, while all chlorinated and one aliphatic OPEs (i.e., TCEP, TCPP, TDCP and TEHP) were found to be recalcitrant to oxidation. Moreover, the presence of HA significantly enhanced the degradation of reactive OPEs in ozone treatment.
\end{abstract}

(c) 2015 Elsevier B.V. All rights reserved.

\section{Introduction}

Organophosphate esters (OPEs) are an important class of commercial additives used in flame retardants, plasticizers, hydraulic fluids, lacquers, solvents, extraction agents, antifoam agents, adhesives, and electronic devices [1]. Many of the OPEs are not chemically bonded to the final products, and thus are easily released to the aquatic environment via domestic sewage, industrial wastewater, and rainfall runoff from construction sites and pavements, as well as through the disposal of OPEs-containing materials [2,3].

OPEs cannot be efficiently removed by conventional biological treatment processes in wastewater treatment plants (WWTPs), resulting in their widespread presence in secondary effluents and surface waters at concentrations ranging from ng $\mathrm{L}^{-1}$ to a few hundred $\mu \mathrm{g} \mathrm{L}^{-1}$ [4-6]. Marklund et al. [7] identified tris(2-butoxyethyl) phosphate (TBEP), tris(chloropropyl) phosphate (TCPP) and tri-n-butyl phosphate (TnBP) as the most abundant OPEs at

\footnotetext{
* Corresponding authors.

E-mail addresses: carmesans@ub.edu (C. Sans), qiangz@rcees.ac.cn (Z. Qiang).
}

concentrations ranging from 0.36 to $30 \mu \mathrm{g} \mathrm{L}^{-1}$ in the effluents of seven Swedish WWTPs. Moreover, chlorinated OPEs including tris(2-chloroethyl) phosphate (TCEP), tris(dichloropropyl) phosphate (TDCP) and TCPP showed an insignificant removal after biological treatment in two German WWTPs and their maximum levels in the effluents were detected to be $0.47,0.31$ and $6.6 \mu \mathrm{g} \mathrm{L}^{-1}$, respectively [8]. Previous studies revealed that TCEP, TCPP, and TDCP were the most recalcitrant and predominant OPEs in the WWTP effluents [1,9]. Although the impacts of these OPEs on aquatic ecosystems and human health are to be determined, there has been increasing interest in their treatment at sources and in WWTPs.

Advanced treatments, such as ozone and $\mathrm{UV} / \mathrm{H}_{2} \mathrm{O}_{2}$, can achieve significant abatement of many organic micropollutants and thus improve the quality of municipal wastewater effluents [10-12]. Ozone may attack organic compounds through either direct oxidation with molecular ozone or indirect oxidation with highly reactive hydroxyl radicals $\left({ }^{\circ} \mathrm{OH}\right)$ depending on the operating conditions. $\mathrm{UV} / \mathrm{H}_{2} \mathrm{O}_{2}$ is based on the in-situ generation of $\mathrm{OH}$, which can unselectively and efficiently oxidize a wide range of 
organic pollutants. Ozone and $\mathrm{UV} / \mathrm{H}_{2} \mathrm{O}_{2}$ treatments are promising technologies because they are able to oxidize micropollutants, transform natural organic matter (NOM), and inactivate pathogens simultaneously [13]. Compared with other advanced treatments such as Fenton's regent oxidation, membrane filtration and activated carbon adsorption, ozone and $\mathrm{UV} / \mathrm{H}_{2} \mathrm{O}_{2}$ have no requirement for $\mathrm{pH}$ adjustment, sludge disposal, membrane backwash, or adsorbent regeneration, thus are commonly applied for water and wastewater treatment $[12,14]$. In addition, water matrix, especially the type and content of natural organic or inorganic matter, can affect the oxidation of organic pollutants by competing for the oxidant and/or affecting the generation of $\mathrm{OH}$ [15-17]. However, there is little research concerning the effect of water matrix on the removal of OPEs in ozone and $\mathrm{UV} / \mathrm{H}_{2} \mathrm{O}_{2}$ treatments.

This study aimed to assess the degradation kinetics of eight widely used OPEs in ozone and $\mathrm{UV} / \mathrm{H}_{2} \mathrm{O}_{2}$ treatments. To examine the effect of water matrix on the degradation of target OPEs, bench-scale experiments were conducted with Milli-Q water, humic acid (HA) solution and municipal secondary effluent spiked with the target OPEs at an environmentally relevant concentration ( $50 \mu \mathrm{g} \mathrm{L}{ }^{-1}$ each). The energy consumption of ozone and $\mathrm{UV} / \mathrm{H}_{2} \mathrm{O}_{2}$ treatments was also comparatively evaluated based on the overall removal efficiencies of target OPEs. This study helps to better control the release of OPEs from WWTPs to the environment.

\section{Materials and methods}

\subsection{Chemicals}

TCEP, TCPP, TDCP, triphenyl phosphate (TPhP), tricresyl phosphate (TCrP), TnBP, TBEP, tris(2-ethylhexyl) phosphate (TEHP), HA sodium salt (Product No. H16752, Lot No. STBD0913V), and ammonium acetate were obtained from Sigma-Aldrich (St. Louis, MO, USA). All the OPE standards were of the highest purity available $(\geqslant 95 \%)$, whose major physico-chemical properties are summarized in Table 1 . The stock solution containing all the studied OPEs was prepared in acetone at a concentration of $1000 \mathrm{mg} \mathrm{L}^{-1}$ and stored in amber glass bottles at $-20{ }^{\circ} \mathrm{C} . \mathrm{H}_{2} \mathrm{O}_{2}$ (30\%, by weight) was supplied by Panreac (Barcelona, Spain). Milli-Q water was produced by an Advantage A10 water purification system (Millipore, Billerica, MA, USA). High performance liquid chromatography grade acetone and methanol (>99\%) were purchased from Merck (Darmstadt, Germany).

\subsection{Sample collection and preparation}

Ozone and $\mathrm{UV} / \mathrm{H}_{2} \mathrm{O}_{2}$ experiments were performed in three different water matrices: Milli-Q water, HA solution and municipal secondary effluent. The HA solution was prepared and filtered through $0.22 \mu \mathrm{m}$ filters (Millipore, Billerica, MA, USA) before use, whose characteristics were as follows: $T O C=4.7 \mathrm{mg} \mathrm{L}^{-1}$, $\mathrm{COD}=36.6 \mathrm{mg} \mathrm{L}^{-1}$, and $\mathrm{pH}=7.3$. Municipal secondary effluent was collected from the Gavà-Viladecans WWTP close to Barcelona (Spain). This facility, serving a population of about 172,000 inhabitants, consisted of screen, grit chamber, primary clarifier, conventional activated sludge process, and secondary clarifier. The secondary effluent was transported to laboratory immediately after collection, filtered through $0.22 \mu \mathrm{m}$ filters to remove suspended solids, and stored in the dark at $4{ }^{\circ} \mathrm{C}$ until use. The characteristics of the filtered municipal secondary effluent are shown in Table 2 .

\subsection{Reaction systems}

Ozone experiments were performed in a $2.0 \mathrm{~L}$ jacketed glass reactor (inner diameter $=9.6 \mathrm{~cm}$, height $=27.7 \mathrm{~cm}$ ) with the reaction solution temperature controlled at $20^{\circ} \mathrm{C}$. Ozone gas stream was injected into the reactor through two stainless steel diffusers at a flow rate of $60 \mathrm{~L} \mathrm{~h}^{-1}$ and with a gaseous ozone concentration of about $10 \mathrm{mg} \mathrm{L}^{-1}$. Detailed description about the ozone treatment system can be found elsewhere [18]. Two ozone analyzers,

Table 1

Major physico-chemical properties of target OPEs.

\begin{tabular}{|c|c|c|c|c|c|c|c|}
\hline Compound (acronym) & CAS no. & $\begin{array}{l}\text { Molecular } \\
\text { formula }\end{array}$ & $\begin{array}{l}\text { Molecular } \\
\text { weight }\end{array}$ & $\begin{array}{l}\text { Henry's } \\
\text { constant a }\end{array}$ & Solubility ${ }^{\mathrm{a}}\left(\mathrm{g} \mathrm{L}^{-1}\right)$ & $\log K_{o w}{ }^{a}$ & Structure $^{b}$ \\
\hline Tris(2-chloroethyl) phosphate (TCEP) & $115-96-8$ & $\mathrm{C}_{6} \mathrm{H}_{12} \mathrm{Cl}_{3} \mathrm{O}_{4} \mathrm{P}$ & 285.48 & 5.98 & 37.06 & 2.67 & \\
\hline Tris(chloropropyl) phosphate (TCPP) & $13674-84-5$ & $\mathrm{C}_{9} \mathrm{H}_{18} \mathrm{Cl}_{3} \mathrm{O}_{4} \mathrm{P}$ & 327.56 & 5.61 & 7.65 & 3.9 & \\
\hline Tris(dichloropropyl) phosphate (TDCP) & $13674-87-8$ & $\mathrm{C}_{9} \mathrm{H}_{15} \mathrm{Cl}_{6} \mathrm{O}_{4} \mathrm{P}$ & 430.89 & 6.97 & 1.94 & 4.99 & \\
\hline Triphenyl phosphate (TPhP) & $115-86-6$ & $\mathrm{C}_{18} \mathrm{H}_{15} \mathrm{O}_{4} \mathrm{P}$ & 326.29 & 6.29 & 0.047 & 5.6 & \\
\hline Tricresyl phosphate (TCrP) & $1330-78-5$ & $\mathrm{C}_{21} \mathrm{H}_{21} \mathrm{O}_{4} \mathrm{P}$ & 368.37 & 6.16 & $7.0 e-3$ & 7 & \\
\hline Tri-n-butyl phosphate (TnBP) & $126-73-8$ & $\mathrm{C}_{12} \mathrm{H}_{27} \mathrm{O}_{4} \mathrm{P}$ & 266.32 & 3.88 & 0.40 & 4.18 & \\
\hline Tributoxyethyl phosphate (TBEP) & $78-51-3$ & $\mathrm{C}_{18} \mathrm{H}_{39} \mathrm{O}_{7} \mathrm{P}$ & 398.48 & 9.31 & 0.13 & 3.68 & \\
\hline Tris(2-ethylhexyl) phosphate (TEHP) & $78-42-2$ & $\mathrm{C}_{24} \mathrm{H}_{51} \mathrm{O}_{4} \mathrm{P}$ & 434.64 & 2.41 & $1.5 \mathrm{e}-4$ & 8.95 & \\
\hline
\end{tabular}

a Calculated by ACD/Lab.

b Predicted by ChemBio Office 2012. 
Table 2

Characteristics of filtered municipal secondary effluent.

\begin{tabular}{lclc}
\hline Parameter & Value & Parameter & Value \\
\hline TOC $\left(\mathrm{mg} \mathrm{L}^{-1}\right)$ & 7.8 & $\mathrm{NH}_{4}^{+}\left(\mathrm{mg} \mathrm{L}^{-1}\right)$ & 13.9 \\
COD $\left(\mathrm{mg} \mathrm{L}^{-1}\right)$ & 28.4 & $\mathrm{Ca}^{2+}\left(\mathrm{mg} \mathrm{L}^{-1}\right)$ & 115.4 \\
UV254 $\left(\mathrm{cm}^{-1}\right)$ & 12.4 & $\mathrm{Mg}^{2+}\left(\mathrm{mg} \mathrm{L}^{-1}\right)$ & 52.1 \\
Inorganic carbon $\left(\mathrm{mg} \mathrm{L}^{-1}\right)$ & 66.5 & $\mathrm{NO}_{3}^{-}\left(\mathrm{mg} \mathrm{L}^{-1}\right)$ & 24.9 \\
pH & 8.2 & $\mathrm{NO}_{2}^{-}\left(\mathrm{mg} \mathrm{L}^{-1}\right)$ & 7.35 \\
Turbidity (NTU) & 1.99 & $\mathrm{SO}_{4}^{2-}\left(\mathrm{mg} \mathrm{L}^{-1}\right)$ & 203.3 \\
Alkalinity (mg L & & & \\
\hline
\end{tabular}

BMT 963 and BMT 964 (BMT Messtechnik, Germany), were installed respectively at the inlet and outlet of the reactor with UV detection at $254 \mathrm{~nm}$. Ozone concentrations digitally displayed by the analyzers were already corrected to the normal temperature and pressure conditions. Each ozone experiment lasted for $120 \mathrm{~min}$. The transferred ozone dose (TOD), defined as the accumulative amount of ozone absorbed by the reaction solution per unit of volume, was calculated based on ozone mass balance as follows:

$\mathrm{TOD}=\int_{0}^{t} \frac{Q_{\text {gas }}}{V_{\text {sol }}} \times\left(\left[\mathrm{O}_{3}\right]_{\text {in }}-\left[\mathrm{O}_{3}\right]_{\text {out }}\right) \times d t$

where $Q_{\text {gas }}, V_{\text {sol }}$ and $t$ represent the gas flow rate, reaction solution volume and reaction time, respectively; and $\left[\mathrm{O}_{3}\right]_{\text {in }}$ and $\left[\mathrm{O}_{3}\right]_{\text {out }}$ represent the gaseous ozone concentrations at the inlet and outlet of the reactor, respectively.

$\mathrm{UV} / \mathrm{H}_{2} \mathrm{O}_{2}$ experiments were carried out in the same glass reactor with the reaction solution temperature controlled at $25^{\circ} \mathrm{C}$. Three low-pressure mercury lamps ( $8 \mathrm{~W}, 26 \%$ UVC efficiency, Philips TUV G8T5) emitting $254 \mathrm{~nm}$ light, with each protected by a quartz sleeve, were placed equidistantly in the reactor. Detailed information about this device can be found in Souza et al. [19]. By using an actinometrical method [19], an incident photon fluence of $1.49 \times 10^{-5} \mathrm{E} \mathrm{s}^{-1}$ was measured, which corresponded to an average fluence rate of $8.04 \mathrm{~mW} \mathrm{~cm}^{-2}$ in the reactor. The UV lamps were initially warmed up outside the reactor for at least 15 min to ensure a relatively stable output. $\mathrm{H}_{2} \mathrm{O}_{2}$ was added to the reactor to reach an initial concentration of $20 \mathrm{mg} \mathrm{L}^{-1}$, and then the lamps were inserted into the quartz sleeves to start the irradiation. Each $\mathrm{UV} / \mathrm{H}_{2} \mathrm{O}_{2}$ experiment lasted for $60 \mathrm{~min}$.

The ozone and $\mathrm{UV} / \mathrm{H}_{2} \mathrm{O}_{2}$ experiments were conducted in triplicate with the $\mathrm{pH}$ of test water unbuffered. A desired volume of the stock solution (i.e., $100 \mu \mathrm{L}$ ) containing all the target OPEs was spiked into a test water matrix to reach an initial concentration of $50 \mu \mathrm{g} \mathrm{L}^{-1}$ for each compound. After the reaction was initiated under magnetic stirring conditions, samples were taken at preselected time intervals for OPEs and/or $\mathrm{H}_{2} \mathrm{O}_{2}$ analysis. The residual ozone in the sample was quenched by $\mathrm{NaHSO}_{3}$, and the residual $\mathrm{H}_{2} \mathrm{O}_{2}$ was quenched by catalase or $\mathrm{NaHSO}_{3}$ depending on the analysis to be performed.

\subsection{Analytical methods}

Chromatographic separation of the target OPEs was performed on an Acquity ultra performance liquid chromatography system (Waters, Milford, MA, USA) equipped with an Eclipse XDB-C18 column $(150 \mathrm{~mm} \times 2.1 \mathrm{~mm}, 5 \mu \mathrm{m})$ (Agilent, Wilmington, DE, USA). The column temperature was maintained at $30^{\circ} \mathrm{C}$ and the injection volume was $50 \mu \mathrm{L}$. Ammonium acetate in methanol (A, $5 \mathrm{mM})$ and Milli-Q water (B) were used as the mobile phases with a total flow rate of $0.3 \mathrm{~mL} \mathrm{~min}{ }^{-1}$. The gradient elution program (time in min, \% mobile phase A) was set as follows: $(0,50),(1,50),(16,100),(20$, $100),(24,50)$, and $(28,50)$. A Triple Quadrupole Detector (Waters, Milford, MA, USA), equipped with an electrospray ionization source and operated in the positive ion mode, was employed to detect the target OPEs. The MS system was operated under the following conditions: capillary voltage $=3.5 \mathrm{kV}$, source temperature $=120^{\circ} \mathrm{C}$, desolvation temperature $=350^{\circ} \mathrm{C}$, nitrogen gas flow rate for desolvation $=550 \mathrm{~L} \mathrm{~h}^{-1}$, cone gas flow rate $=20 \mathrm{~L} \mathrm{~h}^{-1}$, and argon gas flow rate for collision $=0.19 \mathrm{~mL} \mathrm{~min}^{-1}$. For each compound, the cone voltage, collision energy (CE), and multiple reaction monitoring mode (MRM) transitions were optimized (Table 3). MassLynx Workstation Software (V4.1, Waters) was employed for both instrument control and data acquisition/analysis. The OPE concentrations in each sample were analyzed in duplicate. In the tested municipal secondary effluent, it was found that all the studied OPEs were below their method detection limits (i.e., 2-60 $\mathrm{ng} \mathrm{L}^{-1}$ ).

OPE standard samples prepared in water at 5 and $50 \mu \mathrm{g} \mathrm{L}^{-1}$ were injected at the beginning and the end of each injection sequence to check the instrumental variations. For most of the target OPEs, the percent variation was within the ranges of $0-20 \%$ at the $5 \mu \mathrm{g} \mathrm{L}^{-1}$ level and 3-15\% at the $50 \mu \mathrm{g} \mathrm{L}^{-1}$ level, indicating an overall robustness of the method employed. $\mathrm{H}_{2} \mathrm{O}_{2}$ concentration was determined by the metavanadate spectrophotometric method at $450 \mathrm{~nm}$ [20].

\section{Results and discussion}

\subsection{Ozone treatment}

The degradation of target OPEs versus TOD during ozone treatment in Milli-Q water, HA solution and municipal secondary effluent is depicted in Fig. 1, and the observed pseudo-first-order rate constants $\left(k, \min ^{-1}\right)$ in the three water matrices are presented in Fig. 2.

In Milli-Q water, ozone reacted with the target OPEs in a selective way. The aromatic and aliphatic compounds (except TEHP) underwent a fast reaction with ozone, while the chlorinated compounds and TEHP were slowly degraded (Fig. 1a). More than $70 \%$ of the aromatic and aliphatic compounds were removed at $\mathrm{TOD}=9.4 \mathrm{mg} \mathrm{L}^{-1}$, and their reaction rates followed a descending order: TBEP $>$ TPhP $>$ TCrP $>$ TnBP. However, less than $30 \%$ of the chlorinated OPEs (TCPP, TDCP, and TCEP) and TEHP were removed even at $\mathrm{TOD}=31.2 \mathrm{mg} \mathrm{L}^{-1}$, so they can be considered as ozone recalcitrant compounds.

It is well known that ozone reacts with organic compounds through direct oxidation via molecular ozone and indirect oxidation via $\cdot \mathrm{OH}$ generated from a series of chain reactions of ozone with hydroxide ions [21]. In Milli-Q water, the ozonated solution was slightly acidic (pH varying from 5 to 6 ), so the indirect pathway was less important. Molecular ozone selectively attacks organic compounds with electron-rich functional groups such as double bonds, aromatic rings, and deprotonated amines [22]. The aliphatic chains bonded to the phosphate of TnBP increased the reactivity toward ozone, and the presence of heteroatoms $(\mathrm{O})$ in the aliphatic chains of TBEP further promoted the direct ozonation. $\mathrm{TPhP}$ and $\mathrm{TCrP}$, because of their aromatic rings, were also reactive

Table 3

Optimal MS/MS parameters for target OPEs under MRM positive ionization mode.

\begin{tabular}{lllll}
\hline Compound & $\begin{array}{l}\text { Retention } \\
\text { time }(\mathrm{min})\end{array}$ & $\begin{array}{l}\text { Cone } \\
\text { voltage } \\
(\mathrm{V})\end{array}$ & $\begin{array}{l}\text { Quantification } \\
\text { transition }(\mathrm{CE}, \\
\mathrm{eV})\end{array}$ & $\begin{array}{l}\text { Confirmation } \\
\text { transition }(\mathrm{CE}, \\
\mathrm{eV})\end{array}$ \\
\hline TCEP & 5.6 & 30 & $287>99(25)$ & $287>63(25)$ \\
TCPP & 9.7 & 25 & $327>99(25)$ & $329>99(25)$ \\
TDCP & 12.1 & 30 & $431>99(17)$ & $431>209(17)$ \\
TPhP & 12.2 & 45 & $327>152(30)$ & $327>215(30)$ \\
TCrP & 15.0 & 50 & $369>166(28)$ & $369>243(28)$ \\
TnBP & 13.4 & 25 & $267>155(12)$ & $267>99(12)$ \\
TBEP & 14.0 & 35 & $399>199(15)$ & $399>299(15)$ \\
TEHP & 19.9 & 15 & $435>99(9)$ & $435>323(9)$ \\
\hline
\end{tabular}



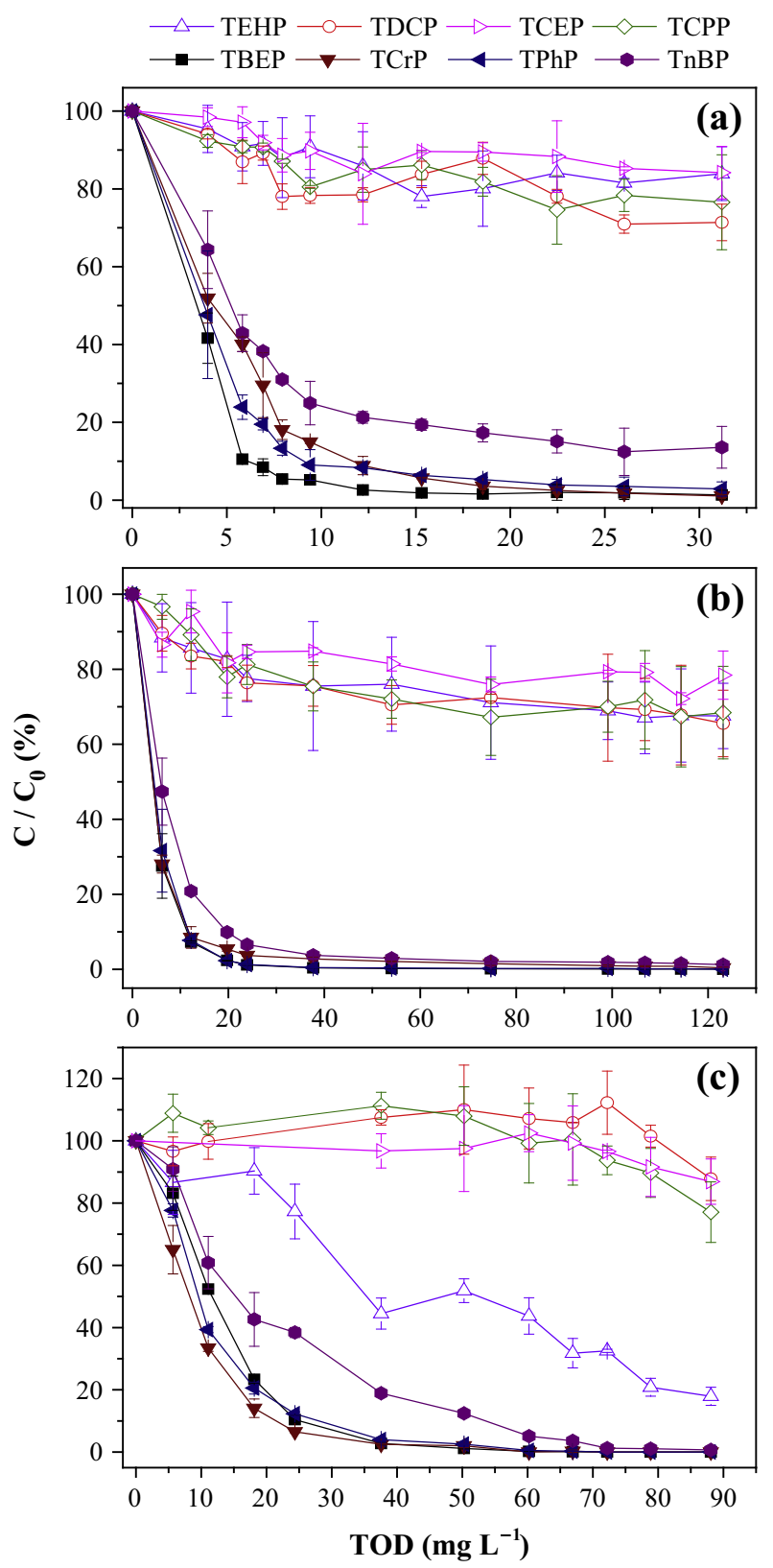

Fig. 1. Removal of target OPEs during ozone treatment as a function of TOD in different matrices: (a) Milli-Q water; (b) HA solution; and (c) municipal secondary effluent. Error bars represent the standard deviations of triplicate experiments.

toward ozone. These OPEs could be classified as ozone reactive species. Concerning the ozone recalcitrant compounds, the presence of $\mathrm{Cl}$ atoms in TCPP, TDCP and TCEP and the ramification of the aliphatic chains of TEHP decreased their reactivity toward ozone (Fig. 2).

NOM is ubiquitous in surface and ground waters. As an important component of NOM, humic substances can directly or indirectly react with ozone [23]. When the target OPEs were exposed to ozone in the presence of HA, more than $80 \%$ of TBEP, TPhP, TCrP and TnBP were degraded at TOD $=12.2 \mathrm{mg} \mathrm{L}^{-1}$ (Fig. 1b). Compared to the case in Milli-Q water, ozonation in HA solution led to significantly faster degradation rates of the reactive OPEs and the degradation rates of TBEP, TPhP, TCrP, and TnBP were also increased by $21 \%, 37 \%, 70 \%$, and $42 \%$, respectively (Fig. 2). Ozonation of HA could inherently lead to considerable $\mathrm{OH}$ production as a result of the reactions between ozone and the electron-rich moieties of HA
[24]. Nevertheless, the produced radicals had little impact on the removal of the recalcitrant OPEs because they were preferentially consumed by the reactive OPEs. Therefore, the removal efficiencies of TCPP, TDCP, TCEP and TEHP were only $32 \%, 35 \%, 22 \%$, and $33 \%$, respectively, at TOD $=123.1 \mathrm{mg} \mathrm{L}^{-1}$.

As shown in Figs. 1c and 2, the degradation rates of target OPEs in municipal secondary effluent were relatively lower than those in Milli-Q water and in HA solution, except TEHP. TBEP, TPhP, and $\mathrm{TCrP}$ were totally removed at $\mathrm{TOD}=50.3 \mathrm{mg} \mathrm{L}^{-1}$, while a total removal of TnBP needed a higher TOD value of $72.2 \mathrm{mg} \mathrm{L}^{-1}$. The removal of chlorinated OPEs was less than $20 \%$ at the end of the reaction. As mentioned above, ozone reaction is highly dependent on the solution $\mathrm{pH}$. The original $\mathrm{pH}$ of the municipal secondary effluent was 8.2 and then remained above 8.0 during the ozonation treatment. Therefore, both the direct oxidation via molecular ozone and the indirect oxidation via $\mathrm{OH}$ would account for the OPEs removal. Note that there were various ions existing in the municipal secondary effluent, including $\mathrm{Cl}^{-}, \mathrm{SO}_{4}^{2-}, \mathrm{HCO}_{3}^{-}$, and $\mathrm{NO}_{3}^{-}$(Table 2), which could act as radical scavengers. More importantly, the effluent organic matter (EfOM) could also react with molecular ozone and $\cdot \mathrm{OH}$, thus considerably impacting the degradation of target OPEs. EfOM is a complex mixture of NOM, soluble microbial products and organic micropollutants, which consists of both dissolved and colloidal organic compounds [25]. EfOM was reported to be the main $\mathrm{OH}$ scavenger in municipal secondary effluents, due to its moderate reactivity toward $\mathrm{OH}$ and its relatively high concentration $[26,27]$. The removal of most of the target OPEs was inhibited because of the complex matrix materials present in the municipal secondary effluent (e.g., EfOM, $\mathrm{CO}_{3}^{2-}, \mathrm{HCO}_{3}^{-}$) that could compete for ozone and ${ }^{\circ} \mathrm{OH}$ [28]; however, the removal of TEHP was enhanced notably through some unknown mechanisms.

\section{2. $\mathrm{UV} / \mathrm{H}_{2} \mathrm{O}_{2}$ treatment}

The degradation of target OPEs during $\mathrm{UV} / \mathrm{H}_{2} \mathrm{O}_{2}$ treatment in Milli-Q water, HA solution and municipal secondary effluent is shown in Fig. 3, and the observed pseudo-first-order rate constants $\left(k, \min ^{-1}\right)$ in the three water matrices are summarized in Fig. 4. Our preliminary experiment had shown that direct UV photolysis for $15 \mathrm{~min}$ (UV fluence $=7200 \mathrm{~mJ} \mathrm{~cm}^{-2}$ ) could remove $100 \%$ of the aromatic TPhP and TCrP, $40 \%$ of TBEP and $18 \%$ of TnBP, but the removal of the chlorinated compounds and TEHP was negligible.

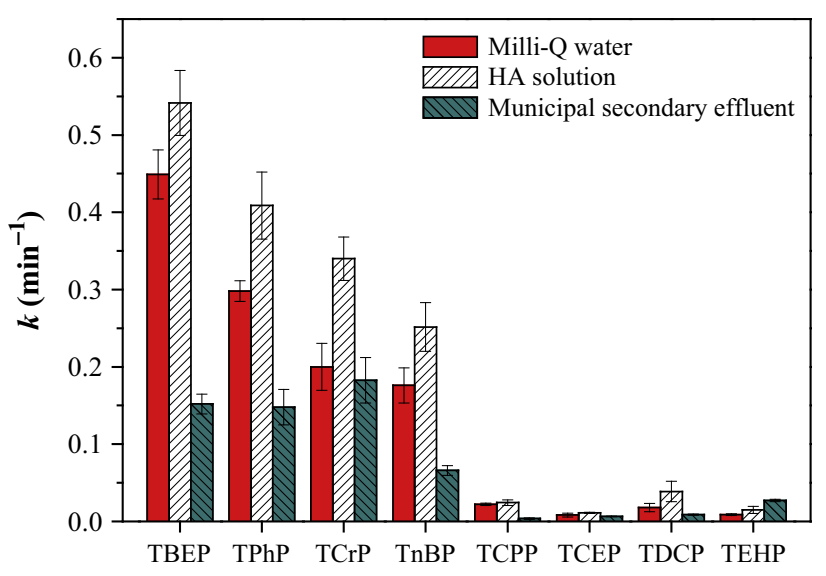

Fig. 2. Comparison of the pseudo-first-order rate constants for the degradation of target OPEs by ozone treatment in different matrices. Error bars represent the standard deviations of triplicate experiments. 

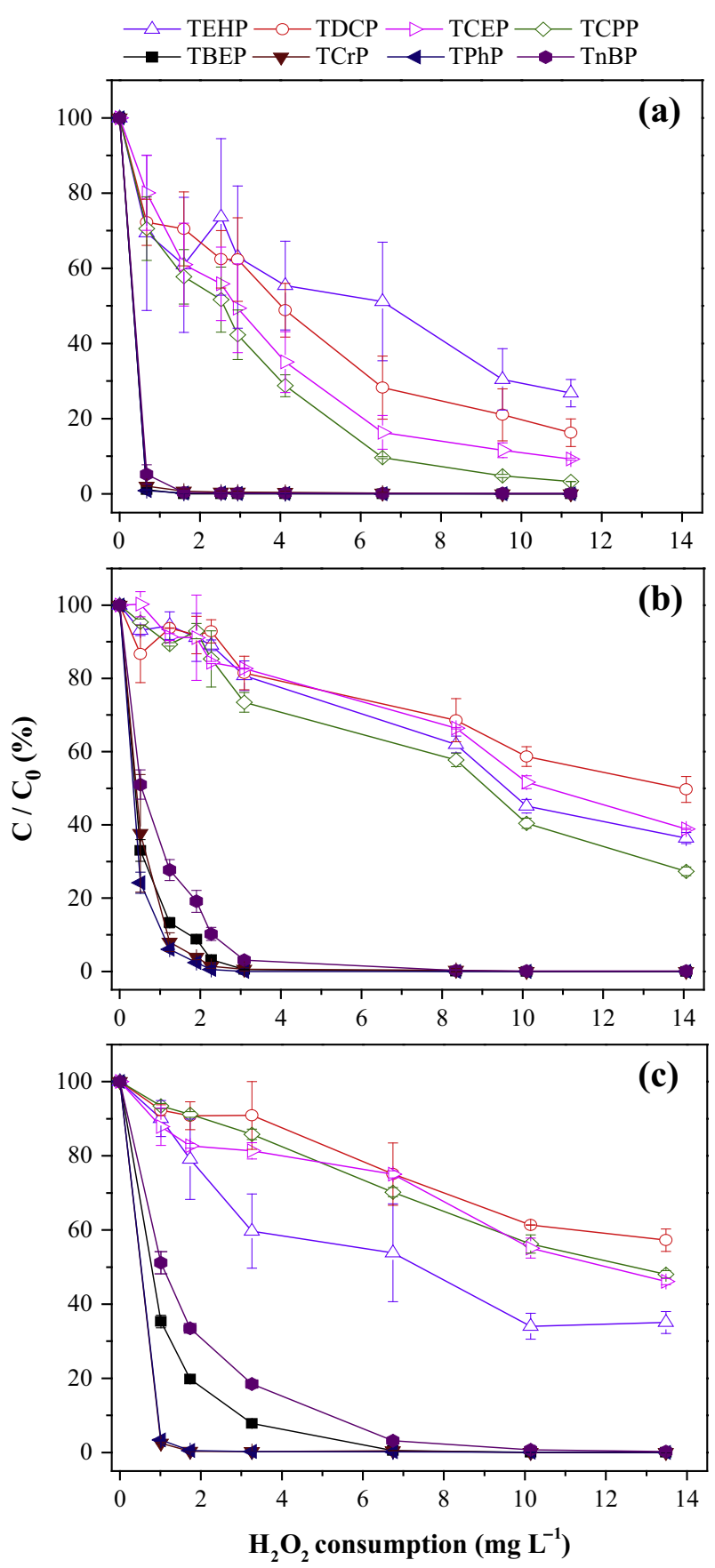

Fig. 3. Removal of target OPEs during $\mathrm{UV} / \mathrm{H}_{2} \mathrm{O}_{2}$ treatment as a function of $\mathrm{H}_{2} \mathrm{O}_{2}$ consumption in different matrices: (a) Milli-O water; (b) HA solution; and (c) municipal secondary effluent. Error bars represent the standard deviations of triplicate experiments.

The reactivity of target OPEs exhibited a similar trend in UV/ $\mathrm{H}_{2} \mathrm{O}_{2}$ to that in ozonation, that is, the recalcitrant OPEs still had relatively lower degradation rates (Fig. 3). In Milli-Q water, the reactive OPEs (TPhP, TCrP, TBEP, and TnBP) were rapidly removed in the first $2 \mathrm{~min}\left(\mathrm{H}_{2} \mathrm{O}_{2}\right.$ consumption $\left.=0.7 \mathrm{mg} \mathrm{L}^{-1}\right)$ (Fig. 3a), which was primarily ascribed to the indirect oxidation of $\cdot \mathrm{OH}$ although direct UV photolysis also made a certain contribution as mentioned above. The electron-rich aromatic rings of TPhP and TCrP were readily attacked by ${ }^{\circ} \mathrm{OH}$, and the heteroatoms $(\mathrm{O})$ in the aliphatic chains of TBEP also increased the reactivity toward $\mathrm{OH}$ [29]. To the contrary, the presence of $\mathrm{Cl}$ atoms in the aliphatic chains of chlorinated OPEs significantly reduced the reactivity toward ${ }^{\circ} \mathrm{OH}$.

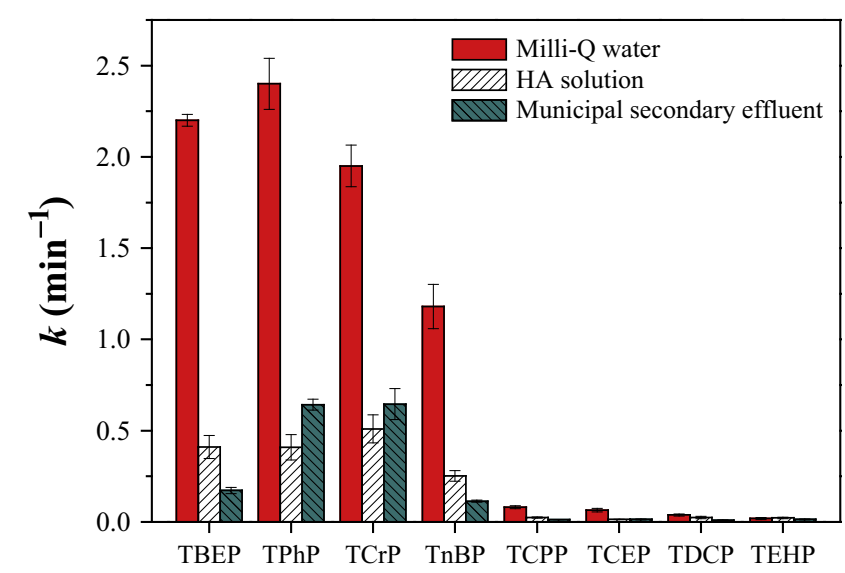

Fig. 4. Comparison of the pseudo-first-order rate constants for the degradation of target OPEs by $\mathrm{UV} / \mathrm{H}_{2} \mathrm{O}_{2}$ treatment in different matrices. Error bars represent the standard deviations of triplicate experiments.

In particular, TDCP, with the highest degree of chlorination, had the lowest degradation rate among the chlorinated OPEs. TEHP was still the least degradable, probably because of the steric effect of its long and ramified chains. After $1 \mathrm{~h}$ reaction, the removal efficiencies of the recalcitrant TCPP, TDCP, TCEP, and TEHP were $97 \%$, $84 \%, 91 \%$ and $74 \%$, respectively (Fig. $3 a$ ).

The degradation of target OPEs was notably inhibited in HA solution, as compared to the results obtained in Milli-Q water (Figs. 3b and 4). The reactive OPEs were removed by more than $90 \%$ in the first $10 \mathrm{~min}\left(\mathrm{H}_{2} \mathrm{O}_{2}\right.$ consumption $\left.=2.3 \mathrm{mg} \mathrm{L}^{-1}\right)$; while after $1 \mathrm{~h}$ reaction, the recalcitrant TCPP, TDCP, TCEP and TEHP were only removed by $72 \%, 53 \%, 61 \%$ and $65 \%$, respectively. On the one hand, UV irradiation of HA may produce $\mathrm{OH}$ and other secondary oxidants to enhance the removal of organic pollutants [30]; on the other hand, the removal of organic pollutants may be inhibited because HA competes for not only UV light against $\mathrm{H}_{2} \mathrm{O}_{2}$ but also 'OH against target pollutants [15,31]. In this study, the inhibitory effect of HA seemed to dominate in the degradation of target OPEs by $\mathrm{UV} / \mathrm{H}_{2} \mathrm{O}_{2}$.

As shown in Figs. 3c and 4, the removal efficiencies of target OPEs in the municipal secondary effluent were generally comparable to those in HA solution. The aromatic OPEs were rapidly removed in the first $5 \mathrm{~min}\left(\mathrm{H}_{2} \mathrm{O}_{2}\right.$ consumption $\left.=1.7 \mathrm{mg} \mathrm{L}^{-1}\right)$; the aliphatic TBEP and TnBP needed 6.7 and $10.1 \mathrm{mg} \mathrm{L}^{-1}$ of $\mathrm{H}_{2} \mathrm{O}_{2}$ consumption to reach a total removal, respectively; and the chlorinated OPEs were removed by less than $55 \%$ at the end of the reaction. Similar to HA, the complex matrix materials in the municipal secondary effluent could compete for UV light and $\cdot \mathrm{OH}$ to inhibit the degradation of target OPEs. Again, it is noted that the degradation of TEHP in the municipal secondary effluent was faster than in HA solution, which is similar to that observed in ozone treatment.

\subsection{Energy consumption}

The energy consumption for ozone and $\mathrm{UV} / \mathrm{H}_{2} \mathrm{O}_{2}$ treatments in the municipal secondary effluent was calculated and compared. The electrical cost in Barcelona (Spain) was $0.125 € \mathrm{~kW} \mathrm{~h}^{-1}$ (February 2014). The $\mathrm{H}_{2} \mathrm{O}_{2}$ consumption cost was also considered and the cost of the laboratorial $\mathrm{H}_{2} \mathrm{O}_{2}$ was $5 € \mathrm{~kg}^{-1}$ ( $30 \%$, by weight). Table 4 shows the electrical energies of UV and ozone together with the $\mathrm{H}_{2} \mathrm{O}_{2}$ cost to treat each cubic meter of municipal secondary effluent with different reaction times. For example, for ozonation with a reaction time of $10 \mathrm{~min}$, the total treatment cost was $0.344 € \mathrm{~m}^{-3}$. The removal of the reactive TBEP, TCrP, TPhP, and 
Table 4

Energy consumption for the degradation of target OPEs during ozone and $\mathrm{UV} / \mathrm{H}_{2} \mathrm{O}_{2}$ treatments in municipal secondary effluent.

\begin{tabular}{|c|c|c|c|c|c|c|c|}
\hline Treatment & $\begin{array}{l}\text { Reaction } \\
\text { time (min) }\end{array}$ & $\begin{array}{l}\text { Ozone energy } \\
\text { cost }\left(€ \mathrm{~m}^{-3}\right)\end{array}$ & 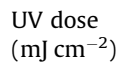 & $\begin{array}{l}\text { UV energy cost } \\
\left(€ \mathrm{~m}^{-3}\right)\end{array}$ & $\begin{array}{l}\mathrm{H}_{2} \mathrm{O}_{2} \text { cost } \\
\left(€ \mathrm{~m}^{-3}\right)\end{array}$ & $\begin{array}{l}\text { Total cost } \\
\left(€ \mathrm{~m}^{-3}\right)\end{array}$ & OPEs removal \\
\hline Ozone & 5 & 0.171 & & & & 0.171 & $\begin{array}{l}\text { TEHP < 10\%; TDCP, TCPP, TCEP < 1\%; TBEP: } 48 \% \text {; TCrP: } \\
67 \% \text {; TPhP: } 61 \% \text {; TnBP: } 39 \%\end{array}$ \\
\hline Ozone & 10 & 0.344 & & & & 0.344 & $\begin{array}{l}\text { TEHP: } 10 \% \text {; TDCP, TCPP, TCEP < 1\%; TBEP: 77\%; TCrP: } \\
\text { 86\%; TPhP: 79\%; TnBP: } 57 \%\end{array}$ \\
\hline Ozone & 30 & 1.031 & & & & 1.031 & $\begin{array}{l}\text { TEHP: 56\%; TDCP, TCPP, TCEP < 5\%; TBEP: } 97 \% \text {; TCrP: } \\
\text { 97\%; TPhP: 96\%; TnBP: } 81 \%\end{array}$ \\
\hline $\mathrm{UV} / \mathrm{H}_{2} \mathrm{O}_{2}$ & 5 & & 2412 & 0.125 & 0.0169 & 0.1414 & $\begin{array}{l}\text { TEHP, TDCP, TCPP, TCEP } \leqslant 12 \% \text {; TBEP: } 65 \% \text {; TCrP: } 98 \% \text {; } \\
\text { TPhP: } 97 \% \text {; TnBP: } 49 \%\end{array}$ \\
\hline $\mathrm{UV} / \mathrm{H}_{2} \mathrm{O}_{2}$ & 10 & & 4824 & 0.25 & 0.029 & 0.279 & $\begin{array}{l}\text { TEHP, TDCP, TCPP, TCEP } \leqslant 21 \% \text {; TBEP: } 80 \% \text {; TCrP: } 100 \% \\
\text { TPhP: } 99 \% \text {; TnBP: } 67 \%\end{array}$ \\
\hline $\mathrm{UV} / \mathrm{H}_{2} \mathrm{O}_{2}$ & 15 & & 7236 & 0.375 & 0.0543 & 0.4293 & $\begin{array}{l}\text { TEHP: 40\%; TDCP, ТCPP, TCEP < 20\%; TBEP: } 92 \% \text {; TCrP: } \\
\text { 100\%; TPhP: } 100 \% \text {; TnBP: } 82 \%\end{array}$ \\
\hline $\mathrm{UV} / \mathrm{H}_{2} \mathrm{O}_{2}$ & 30 & & 14472 & 0.75 & 0.1123 & 0.8623 & $\begin{array}{l}\text { TEHP: } 46 \% \text {; TDCP, ТCPP, TCEP } \leqslant 30 \% \text {; ТЕP: } 100 \% \text {; TCrP } \\
\text { 100\%; TPhP: } 100 \% \text {; TnBP: } 97 \%\end{array}$ \\
\hline
\end{tabular}

TnBP varied from $57 \%$ to $86 \%$, while the removal of the recalcitrant TEHP, TDCP, TCPP and TCEP were almost negligible $(<10 \%)$. For UV/ $\mathrm{H}_{2} \mathrm{O}_{2}$ with a reaction time of $10 \mathrm{~min}$, the total treatment cost was $0.279 € \mathrm{~m}^{-3}$. The reactive OPEs were removed by $67-100 \%$, while the recalcitrant OPEs were removed by $9-21 \%$. Therefore, UV/ $\mathrm{H}_{2} \mathrm{O}_{2}$ appeared to be more efficient than ozone in regard to the removal of OPEs in the municipal secondary effluent.

In addition, it is seen that the cost for ozone generation or UV irradiation occupied a primary portion of the total cost in ozone and $\mathrm{UV} / \mathrm{H}_{2} \mathrm{O}_{2}$ treatments, respectively. Although this economical assessment is quite simple and does not consider other operation and maintenance costs, it provides some practical considerations about the OPEs removal by ozone and $\mathrm{UV} / \mathrm{H}_{2} \mathrm{O}_{2}$ treatments in municipal secondary effluent.

\section{Conclusions}

Advanced treatments (ozone and $\mathrm{UV} / \mathrm{H}_{2} \mathrm{O}_{2}$ ) were evaluated for the degradation of eight widely used OPEs at an environmental relevant concentration ( $50 \mu \mathrm{g} \mathrm{L}^{-1}$ each) in Milli-Q, HA solution, and municipal secondary effluent. The degradation of target OPEs followed the pseudo-first-order kinetics, and $\mathrm{UV} / \mathrm{H}_{2} \mathrm{O}_{2}$ exhibited better performance than ozone in terms of removal efficiency and energy consumption. The aromatic TPhP and TCrP as well as the aliphatic TBEP and TnBP were rapidly degraded by ozone and $\mathrm{UV} / \mathrm{H}_{2} \mathrm{O}_{2}$, while the chlorinated TCPP, TDCP and TCEP together with the ramified aliphatic TEHP were more recalcitrant to oxidation. Compared to that in Milli-Q water, the presence of HA significantly enhanced the degradation of reactive OPEs in ozone treatment, but an opposite trend was observed in $\mathrm{UV} / \mathrm{H}_{2} \mathrm{O}_{2}$ treatment. Because a significant part of the recalcitrant OPEs still remained in the municipal secondary effluent after ozone or $\mathrm{UV} / \mathrm{H}_{2} \mathrm{O}_{2}$ treatment, further study is required to develop more effective treatment processes, identify major degradation byproducts, and determine the solution toxicity variation.

\section{Acknowledgements}

This research was financially supported by the People Programme (Marie Curie Actions) of the European Union's Seventh Programme FP7/2007-2013 under REA grant (Agreement No. 318926), the Ministry of Education and Innovation of Spain (CTM2008-03263/TECNO, BES-2009-016460), and the Ministry of Housing and Urban-Rural Development of China (2012ZX07313001-07).

\section{References}

[1] T. Reemtsma, J.B. Quintana, R. Rodil, M. García-López, I. Rodríguez, Organophosphorus flame retardants and plasticizers in water and air I. Occurrence and fate, TrAC, Trends Anal. Chem. 27 (2008) 727-737.

[2] I. van der Veen, J. de Boer, Phosphorus flame retardants: properties, production, environmental occurrence, toxicity and analysis, Chemosphere 88 (2012) 1119-1153.

[3] I. Rodríguez, F. Calvo, J.B. Quintana, E. Rubí, R. Rodil, R. Cela, Suitability of solidphase microextraction for the determination of organophosphate flame retardants and plasticizers in water samples, J. Chromatogr. A 1108 (2006) $158-165$.

[4] E. Martínez-Carballo, C. González-Barreiro, A. Sitka, S. Scharf, O. Gans, Determination of selected organophosphate esters in the aquatic environment of Austria, Sci. Total Environ. 388 (2007) 290-299.

[5] T. Reemtsma, S. Weiss, J. Mueller, M. Petrovic, S. González, D. Barcelo, F. Ventura, T.P. Knepper, Polar pollutants entry into the water cycle by municipal wastewater: a European perspective, Environ. Sci. Technol. 40 (2006) 54515458.

[6] R. Rodil, J.B. Quintana, T. Reemtsma, Liquid chromatography-tandem mass spectrometry determination of nonionic organophosphorus flame retardants and plasticizers in wastewater samples, Anal. Chem. 77 (2005) 3083-3089.

[7] A. Marklund, B. Andersson, P. Haglund, Organophosphorus flame retardants and plasticizers in Swedish sewage treatment plants, Environ. Sci. Technol. 39 (2005) 7423-7429.

[8] J. Meyer, K. Bester, Organophosphate flame retardants and plasticisers in wastewater treatment plants, J. Environ. Monit. 6 (2004) 599-605.

[9] R. Rodil, J.B. Quintana, E. Concha-Graňa, P. López-Mahía, S. MuniateguiLorenzo, D. Prada-Rodríguez, Emerging pollutants in sewage, surface and drinking water in Galicia (NW Spain), Chemosphere 86 (2012) 1040-1049.

[10] S. Esplugas, D.M. Bila, L.G.T. Krause, M. Dezotti, Ozonation and advanced oxidation technologies to remove endocrine disrupting chemicals (EDCs) and pharmaceuticals and personal care products (PPCPs) in water effluents, J. Hazard. Mater. 149 (2007) 631-642.

[11] M. Klavarioti, D. Mantzavinos, D. Kassinos, Removal of residual pharmaceuticals from aqueous systems by advanced oxidation processes, Environ. Int. 35 (2009) 402-417.

[12] K. Ikehata, N.J. Naghashkar, M.G. Ei-Din, Degradation of aqueous pharmaceuticals by ozonation and advanced oxidation processes: a review, Ozone-Sci. Eng. 28 (2006) 353-414.

[13] W.T.M. Audenaert, D. Vandierendonck, S.W.H. Van Hulle, I. Nopens, Comparison of ozone and $\mathrm{HO}^{\bullet}$ induced conversion of effluent organic matter (EfOM) using ozonation and $\mathrm{UV} / \mathrm{H}_{2} \mathrm{O}_{2}$ treatment, Water Res. 47 (2013) 23872398.

[14] R. Broséus, S. Vincent, K. Aboulfadl, A. Daneshvar, S. Sauvé, B. Barbeau, M. Prévost, Ozone oxidation of pharmaceuticals, endocrine disruptors and pesticides during drinking water treatment, Water Res. 43 (2009) 4707-4717.

[15] H. Yuan, X.F. Zhou, Y.L. Zhang, Degradation of acid pharmaceuticals in the UV/ $\mathrm{H}_{2} \mathrm{O}_{2}$ process: effects of humic acid and inorganic salts, Clean-Soil Air Water 41 (2013) 43-50.

[16] C. Baeza, D.R.U. Knappe, Transformation kinetics of biochemically active compounds in low-pressure UV photolysis and $\mathrm{UV} / \mathrm{H}_{2} \mathrm{O}_{2}$ advanced oxidation processes, Water Res. 45 (2011) 4531-4543.

[17] M.O. Buffle, J. Schumacher, S. Meylan, M. Jekel, U. von Gunten, Ozonation and advanced oxidation of wastewater: effect of $\mathrm{O}_{3}$ dose, $\mathrm{pH}$, DOM and $\mathrm{HO}^{\circ}-$ scavengers on ozone decomposition and $\mathrm{HO}^{\bullet}$ generation, Ozone-Sci. Eng. 28 (2006) 247-259.

[18] B. Domenjoud, C. Tatari, S. Esplugas, S. Baig, Ozone-based processes applied to municipal secondary effluents, Ozone-Sci. Eng. 33 (2011) 243-249.

[19] B.S. Souza, R.F. Dantas, M. Agulló-Barceló, F. Lucena, C. Sans, S. Esplugas, M. Dezotti, Evaluation of $\mathrm{UV} / \mathrm{H}_{2} \mathrm{O}_{2}$ for the disinfection and treatment of municipal 
secondary effluents for water reuse, J. Chem. Technol. Biot. 88 (2013) 16971706.

[20] R.F.P. Nogueira, M.C. Oliveira, W.C. Paterlini, Simple and fast spectrophotometric determination of $\mathrm{H}_{2} \mathrm{O}_{2}$ in photo-Fenton reactions using metavanadate, Talanta 66 (2005) 86-91.

[21] J. Hoigné, H. Bader, The role of hydroxyl radical reactions in ozonation processes in aqueous solutions, Water Res. 10 (1976) 377-386.

[22] X.H. Jin, S. Peldszus, P.M. Huck, Reaction kinetics of selected micropollutants in ozonation and advanced oxidation processes, Water Res. 46 (2012) 65196530.

[23] U. von Gunten, Ozonation of drinking water: Part I. Oxidation kinetics and product formation, Water Res. 37 (2003) 1443-1467.

[24] C. Zwiener, F.H. Frimmel, Oxidative treatment of pharmaceuticals in water Water Res. 34 (2000) 1881-1885.

[25] H.K. Shon, S. Vigneswaran, S.A. Snyder, Effluent organic matter (EfOM) in wastewater: constituents, effects, and treatment, Crit. Rev. Environ. Sci. Technol. 36 (2006) 327-374.
[26] O.S. Keen, G. McKay, S.P. Mezyk, K.G. Linden, F.L. Rosario-Ortiz, Identifying the factors that influence the reactivity of effluent organic matter with hydroxyl radicals, Water Res. 50 (2014) 408-419.

[27] F.L. Rosario-Ortiz, S.P. Mezyk, D.F.R. Doud, S.A. Snyder, Quantitative correlation of absolute hydroxyl radical rate constants with non-isolated effluent organic matter bulk properties in water, Environ. Sci. Technol. 42 (2008) 5924-5930.

[28] J. Staehelin, J. Hoigné, Decomposition of ozone in water in the presence of organic solutes acting as promoters and inhibitors of radical chain reactions, Environ. Sci. Technol. 19 (1985) 1206-1213.

[29] M.J. Watts, K.G. Linden, Advanced oxidation kinetics of aqueous trialky phosphate flame retardants and plasticizers, Environ. Sci. Technol. 43 (2009) 2937-2942.

[30] D. Vogna, R. Marotta, R. Andreozzi, A. Napolitano, M. d'Ischia, Kinetic and chemical assessment of the $\mathrm{UV} / \mathrm{H}_{2} \mathrm{O}_{2}$ treatment of antiepileptic drug carbamazepine, Chemosphere 54 (2004) 497-505.

[31] O. González, A. Justo, J. Bacardit, E. Ferrero, J.J. Malfeito, C. Sans, Characterization and fate of effluent organic matter treated with $\mathrm{UV} / \mathrm{H}_{2} \mathrm{O}_{2}$ and ozonation, Chem. Eng. J. 226 (2013) 402-408. 